\title{
Save the hearing, an ear surgery training project program to combat deafness in developing countries
}

\author{
Mohamed A. El-Begermy ${ }^{1}$, Hany A. Deghady ${ }^{2}$, Nasr El-Seidy ${ }^{3}$, Abdelrahman Ezzat ${ }^{4}$, Marwa M. El-Begermy ${ }^{1 *}$ (D), \\ Abdul Wasa AlAqel ${ }^{5}$, Mohmed Saleh Mosleh ${ }^{5}$, Yasser Nafie ${ }^{6}$ and Many Others
}

\begin{abstract}
Background: Hearing loss is one of the most common health problems affecting people in the developing countries so our aim of the "Save The Hearing Project" was to combat deafness by training local doctors for ear surgery in order to treat their local patients with low cost as possible. The project was done as ear surgery campaigns in peripheral areas in Egypt, Yemen, and other countries, to train young ENT specialists and to treat patients there. Our plan was put according to the frequency of different causes of deafness as shown by previous surveys. We used the previous local and evidence-based researches to make our protocols of management of different diseases. These protocols were further evaluated during our work.

The project has five stages. The first stage included management of sudden sensory neural hearing loss (SSNHL), otitis media with effusion (OME), and local anesthesia for the ear surgery—cartilage tympanoplasty and ossiculoplasty. The second stage included mastoidectomy cholesteatoma surgery and otoendoscopy. The third stage included more advanced surgery as stapedectomy and tympanosclerosis. The fourth stage included combating SNHL mainly through audiology and rehabilitation program, beside referral for cochlear implants to specialized centers. The fifth stage was only a plan for doing stem cell research in management of hearing loss.
\end{abstract}

Results: Our teams did about 42 campaigns only and the data of 31 were recorded. There were 259 attendants, 70 had hands on training, and 35 were well trained and became trainers. We did 270 tympanoplasties, 52 mastoidectomies, and cholesteatoma surgery beside 16 operations of stage III.

Conclusion: Training an ear surgeon is a tedious and long process, but it is at the end very fruitful and useful for the community. Most causes of $\mathrm{HL}$ are preventable. We think that our project plan to combat $\mathrm{HL}$ is very suitable to be applied in developing countries in Africa and the Middle East.

Keywords: Save hearing, Hearing loss, Ear surgery training, Deafness in Egypt, Avoid deafness

\section{Background}

Hearing loss (HL) is one of the most common health problems affecting people around the world. It can affect any age and it has many causes. In Egypt, it affects 16\% of the population [1]. In children under 14 years old, the incidence of $\mathrm{HL}$ was $14 \%$. Conductive (CHL) was found

\footnotetext{
* Correspondence: marwabegermy@gmail.com

'ENT department, Ain Shams University, Cairo, Egypt

Full list of author information is available at the end of the article
}

in $86 \%$ of them, and sensory neural (SNHL) in $14 \%$. In Egypt, HL was more in males (60\%) than females (40\%) [2]. A high prevalence of hearing impairment was also reported in Africa [3]. In Uganda, 11.7\% of subjects below 15 years of age had HL [3]. There is evidence suggesting that the prevalence of hearing impairment is higher than reported and that much of it is avoidable or treatable [3, 4]. HL in children may be a cause of delayed development of language, speech, and cognitive skills so early diagnosis and treatment is mandatory. In adults, it

\section{Springer Open}

(c) The Author(s). 2020 Open Access This article is licensed under a Creative Commons Attribution 4.0 International License, which permits use, sharing, adaptation, distribution and reproduction in any medium or format, as long as you give appropriate credit to the original author(s) and the source, provide a link to the Creative Commons licence, and indicate if changes were made. The images or other third party material in this article are included in the article's Creative Commons licence, unless indicated otherwise in a credit line to the material. If material is not included in the article's Creative Commons licence and your intended use is not permitted by statutory regulation or exceeds the permitted use, you will need to obtain permission directly from the copyright holder. To view a copy of this licence, visit http://creativecommons.org/licenses/by/4.0/. 
decreases the individual's ability to communicate with others, causing feelings of loneliness and isolation [4].

\section{Aim of "Save The Hearing" project}

The aim of this project is to combat deafness by training local doctors in developing countries on evidence-based management of HL and ear surgery in order to treat their local patients with low cost as possible.

\section{History: how the idea became a project}

Professor S. Soliman in Ain Shams University (ASU) (1979) conducted a survey to know the magnitude of deafness in rural areas in Egypt, and the incidence of otitis media was about $2.5 \%$ of the examined population. The needed equipment to do the surgery were available in ministry of health hospitals but trained surgeons were not enough to do surgery. This aroused me to submit the first written project of temporal bone dissection course (TBDC) in 1986. The temporal bone lab was established under supervision of Prof. Magdy Hamed (1995). And I had the honor to be a demonstrator, lecturer, and then the head of the TBD lab till 2012.

Although TBDC is the most important step, yet it is not all ear surgery. Soft tissue dissection and tympanic membrane reconstruction, which are needed in all tympanoplasty operations, were lacking in the training. Also, wrong decision-making was prevailing among many trainees as they thought that tympanoplasty is equal to mastoidectomy although the latter was not needed in most ear surgeries. Besides, there was also a lack of knowledge about the magnitude of different causes of hearing loss and the proper protocol to manage them.

Ear surgery campaigns were done in remote hospitals to treat and to teach local ear surgeons. We designed 5 stages for these campaigns which began as sporadic efforts in the early nineties. The Islamic Medical Association (IMA) of Egypt adopted this project to combat HL from 2012 till 2015. The project was shared also by ministry of health hospitals in Egypt, ASU, and Al-Azhar University members, beside some Arab and African countries (look list of contributors). Another twentyfour training campaigns were done in Egyptian provinces during that time; clever trained surgeons became trainers to continue their work locally.

In Yemen, we began in 1997 till 2008, at al Asaad Hospital in Taiz. Several Yemeni doctors worked with me, the program leader, as assistants, and many attended my operations beside the other scientific activities. Also, 2 competent surgeons were prepared in our ENT department (ASU).

In 2006, I supervised a training course (in all ENT branches) for 14 candidates of the Arab Board in Kuwait hospital of Sana'a University for 6 weeks; it included hands-on ear surgery training. This was followed by TBDC, ASU, Cairo.
Now in Yemen, we have more than 30 competent trained surgeons; many of them became trainers for their junior colleagues. They have independent training teams. I am very proud of my Yemeni colleagues and their achievements which are still going on.

\section{Methods}

\section{Survey of hearing loss in Egypt}

The first step was to know the causes of hearing loss and the frequency of each cause. The work program was planned according to this knowledge. We depended on previous and relatively recent studies done in ASU supported by WHO $[1,2]$. The data of these researches were plotted in Fig. 1.

From Fig. 1, we can conclude that the most frequent cause of hearing loss was otitis media with effusion (OME) and Eustachian tube dysfunction (ED) (40\%) followed by chronic suppurative otitis media (13\%) mostly of the simple tubo-tympanic type (9\%) and less frequent the cholesteatoma type (4\%). So, the first and the second teaching stages were directed to treat these diseases. The third stage is advanced training directed to treat less frequent causes of hearing loss (8.5\%) as otosclerosis and atelectatic ME. The fourth stage is directed to treat SNHL, and most of them (28\%) need hearing aids. This was provided by the audiology team. Severe SNHL was found in $8 \%$, and only $1.7 \%$ need cochlear implants $(\mathrm{CI})$ which was done by more specialized governmental centers. The fifth stage is planned to do stem cell research to treat profound SNHL as a cheap alternative for cochlear implants, if it is successful.

\section{The ear surgery campaigns}

Trainers: $2-4$ training personnel were needed. The campaign program lasted for 2-4 days, done in the local district hospitals.

Candidates: attendance of 10-30 ENT specialists interested to do ear surgery, 2-6 of them were trained as hands on and the rest were observers for another chance. Candidates chosen for hands on should have at least master degree and did TBDC.

Equipment: the local hospital should have examination equipment, audiometers for hearing evaluation, lecture room with data show for presentations, operating rooms equipped with 1-2 surgical microscopes with camera and monitors, micro-instrument sets, and drill. Also, the local hospital should have requirements for general and local anesthesia. They also should prepare local patients for surgery according to the campaign stage.

Portable equipment were also brought by the campaign supervisors including 1-2 microscopes with camera and monitor, 3-4 sets of ear micro-instruments, portable drills and burr terminals, with local anesthesia (LA) requirements, beside teaching tools as printed 


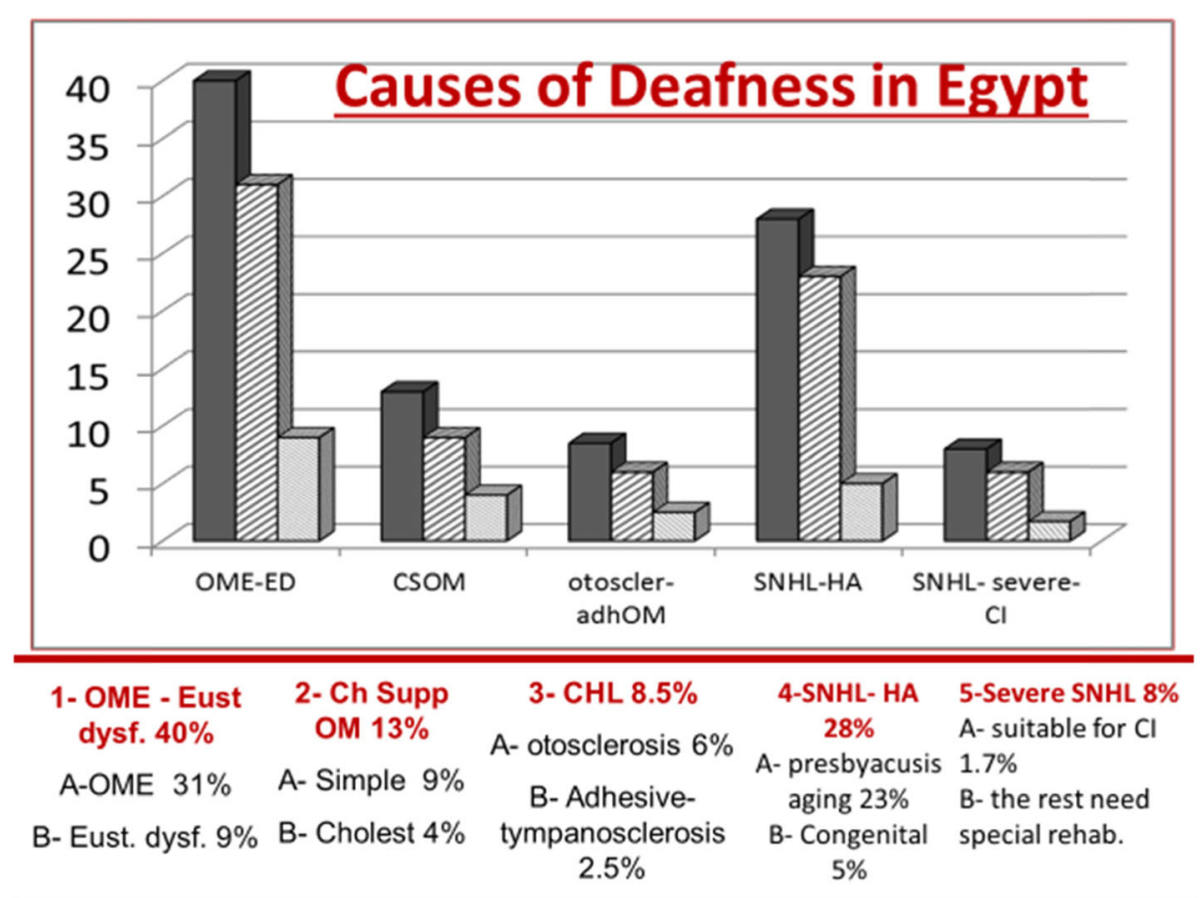

Fig. 1 Causes of deafness in Egypt. Hatched column refers to the more frequent cause, the light one refers to the less frequent one as cited below the columns, and the black column refers to the sum of both

notes, power point presentations, and operative videos which were given to the attending candidates.

Program: each campaign had theoretical lectures introducing the program and practical training including methods of examination, decision-making, and the surgical procedures. Demonstration of the procedures was first done by the supervisors, then candidates did these procedures using well-defined, repeatable steps at least twice in the course under supervision of their trainers. Then they did surgery later on, under supervision of their senior colleagues in their local hospitals. Those who were well trained can help as trainers or supervisors in the next courses. To spread this knowledge, a moral obligatory agreement was done that everyone who becomes well trained should teach and train at least ten of his younger colleagues.

The program was divided into five stages or educational levels. Each campaign concentrates on one stage only as possible. We concentrated on the first 3 stages.

\section{The first stage: basic ear surgery which included the following:}

1. Knowledge of basic surgical anatomy

2. Clinical methods of examination and evaluation with decision-making. This includes methods of exam (microscopic and endoscopic), hearing evaluation (PTA, tympanometry, and ABR), imaging (X-ray, CT scan, and MRI).
3. Protocol for management of sudden sensory neural hearing loss (SSNHL) (Appendix 1) as an emergency, early management may save a patient from permanent hearing loss $[5,6]$.

4. Protocol for local anesthesia in ear surgery as it has many advantages, reduces markedly the surgical costs and complications [7-9].

5. Evidence-based treatment protocol for OME was put and applied in 6 steps (Appendix 2) [10]. Local researches were mainly considered stressing on the role of endoscopy in management [11], peritubal adenoidectomy [12], steroid therapy [13], and the role of milk allergy [14]. The protocol was further evaluated after application.

6. Different methods of middle ear exploration, (permeatal, endaural, postauricular, and endoscopic) and their indications

7. Tympanic membrane reconstruction using tragal cartilage graft as it has high success rate in beginners' hand and less incidence of reperforation [15]. Also, fascia graft is another option for those who prefer it.

8. Regain ossicular continuity mostly with the cartilage graft [15], or using preserved homograft ossicles [16]

9. Butterfly grafts for small residual perforations with healthy middle ear [17]

10. Postoperative care: using special ointment applicator [18], to protect the graft from infection till complete healing 
11. Medical management of acute inflammations of the middle and external ears

The practical training included intratympanic injection, tympanostomy tube application, adenoidectomy (specially peritubal adenoids), local anesthesia, aural polypectomy, cartilage tympanoplasty, and butterfly grafts.

\section{The second stage: mastoidectomy and cholesteatoma surgery}

In this stage, our aim was to teach different types of mastoidectomy and cholesteatoma surgery, beside the use of endoscopy in ear surgery. One of the prerequisites to share as hands on is prior training on temporal bone dissection course (TBDC). Mastoidectomy training included decisionmaking specially when to do it with tympanoplasty.

Cholesteatoma management protocol included patient evaluation and decision-making depending on endoscopic examination, audiometry, and CT findings. Cartilage grafts were used to reconstruct the tympanic membrane and the attic wall [19]. The surgical protocol was published before by the authors [20, 21]. In most cases (with sclerosed mastoid cavity), canal wall down (CWD) using retrograde attico-antrostomy with variable extent of mastoidectomy following the extension of cholesteatoma was done. This was followed by endoscopic control of hidden areas [20] then partial or complete obliteration of the cavity [21], then followed by tympanoossicular reconstruction with cartilage graft [19] and homograft ossicles [16]. In some cases, with wellpneumatized mastoid, posterior approach was used.

\section{The third stage: advanced training}

It was applied for expert surgeons and trainers. It included the following: management of otosclerosis with the classic endaural approach. Endoscopy provided good exposure and assistance [22]. Tympanosclerosis is common in Yemen, and it is managed according to its site and extent [23]. For atelectatic ME, we use TM cartilage graft and regain Eustachian tube function [24]. Congenital aural meatal atresia is treated through posterior approach as it is safer than anterior trans-canal approach [25]. Glomus tympanicum needs hypo-tympanotomy with endoscopic assistance [26]. Facial nerve decompression and grafting are very important if happened due to malpractice from any colleague.

An audiology program was added to stages I, II, and III including the following: training local audiologists on hearing evaluation and screening programs beside training the local ENT surgeons to read and interpret basic hearing evaluation including pure tone audiometry, speech audiometry, and tympanometry and how to make surgical decisions based on the audiological evaluation besides education about how to avoid SNHL.

\section{The fourth stage: management of SNHL and screening of HL}

This stage included an audiological, rehabilitation, education, and screening program, which included the following:

1. Neonatal hearing screening using $\mathrm{OAE}$ and screening ABR. Those who failed in screening tests were sent to full hearing evaluation and rehabilitation in specialized centers.

2. Screening for OME and Eustachian dysfunction using tympanometry in infants and children

3. Screening for adults with SNHL and elderly having presbycusis and refer to get hearing aids (HA)

4. Audiological evaluation and referral of $\mathrm{CI}$ cases

The fifth stage was a research plan for using stem cells in management of SNHL as a cheap alternative for CI. We stopped at the stage of meta-analysis and systematic review. The inconvenient situations in developing countries limited the progress of this research.

\section{Results}

In Egypt, 24 campaigns were done from May 2012 till August 2015. Many campaigns were done before that. Most of them were only 1 day scientific lectures and operative demonstration without training. Only the available data were presented in Table 1.

\section{Other countries}

Tables 2, 3, and 4

\section{Discussion}

Hearing loss is one of the most common health problems affecting people around the world with an average international incidence of 5\% [4]. In Egypt, it affects 16\% of the population [1] with an incidence of $14 \%$ in children less than 14 years old. Eighty-six percent of deaf patients had conductive hearing loss (CHL), while SNHL was found in $14 \%$, with a male to female ratio of 3:2 HL [2]. A high prevalence of hearing impairment was also reported in Africa [3]. In Uganda, $11.7 \%$ of subjects under 15 years of age had HL [3]. There is evidence suggesting that the prevalence of hearing impairment is higher than reported and that much of it is avoidable or treatable [3].

In children, $60 \%$ of hearing loss is attributable to preventable causes. This figure is higher in low- and middleincome countries (75\%) as compared to high-income countries (49\%) [4]. Neglected HL in children may lead to delayed language and cognitive skill development. So early diagnosis and treatment are mandatory.

Overall, preventable causes of childhood hearing loss include the following: infections such as mumps, measles, rubella, meningitis, and cytomegalovirus infections, 
Table 1 Shows the campaigns' data in Egypt. It shows date and place also numbers of days of campaign, trainers, attendance, and hands on trainees. I, II, and III refer to the stage of the program in stage I; myringoplasties presented other operation of the program are not listed. Most operations were done under local anesthesia

\begin{tabular}{|c|c|c|c|c|c|c|c|c|c|}
\hline Date & City, town & Hospital & Days & Trainers & Attendance & Hands on & 1 & $\|$ & III \\
\hline 2002 & Aswan & General H & 3 & 1 & 3 & 1 & 5 & & \\
\hline 2005 & External Oases & Oases General H & 2 & 1 & 2 & - & 2 & & \\
\hline 2006 & M. Matrouh & General H & 2 & 1 & 2 & 2 & 8 & 2 & \\
\hline 2012 & Shebin El kom 1 & El-Helal Insurance H & 1 & 1 & 20 & 2 & 2 & & \\
\hline April 2013 & Damanhur & Dar-Elsalam & 2 & 3 & 20 & 8 & 8 & & \\
\hline May 2013 & Samanoud & General H & & & & & & & \\
\hline 5 June 2013 & Sohaj & Insurance $\mathrm{H}$ & 5 & 4 & 25 & 8 & 10 & 3 & 2 \\
\hline Feb. 2014 & Shebeen Kanater & IMA Hosp. & 1 & 1 & 4 & 1 & 4 & - & - \\
\hline 1-2 May 2014 & Kafr el Sheik 1 & General H & 2 & 3 & 18 & 4 & 7 & - & - \\
\hline 28, 29 August 2014 & Banha 1 & Banha Teach & 2 & 3 & 20 & 5 & 9 & - & \\
\hline 17 December 2014 & Cairo & Matareya H & 1 & 1 & 10 & 1 & 3 & 1 & \\
\hline 1 Jan. 2015 & Cairo & Al Sahel H & 2 & & 25 & 6 & 7 & 2 & \\
\hline 20-21 May 2015 & Kafr el Sheikh 2 & General H & 2 & 3 & 15 & 4 & 6 & 2 & - \\
\hline 30 July 2015 & Shebin El kom 2 & El-Helal Insurance $\mathrm{H}$ & 1 & 1 & 10 & 2 & 4 & & 1 \\
\hline 17 August 2015 & Cairo & Almatareya & 2 & 3 & 25 & 6 & 6 & 3 & \\
\hline 21 August 2015 & Banha 2 & Banha Teach & 2 & 3 & 20 & 6 & 6 & 3 & 1 \\
\hline 26, 27 August 2015 & Damietta & Al Azhar U & 2 & 3 & 15 & 6 & 4 & 2 & 3 \\
\hline 2015 & Samanoud & General H & 2 & 4 & 25 & 8 & 9 & 3 & \\
\hline Sum & 17 & & 34 & & 259 & 70 & 100 & 21 & 7 \\
\hline
\end{tabular}

which can be avoided by the obligatory vaccinations. Use of ototoxic dugs can be avoided by increasing the patients and pediatricians' awareness about their complications. The largest sector causing HL is chronic otitis media which accounts for about 60\% of HL in Egypt (including OME, simple CSOM and cholesteatoma, AME, and tympanosclerosis) (Fig. 1). Our project is directed mainly to this category of patients. This project was also discussed in local conferences in Egypt and Tanzania [27]. The similarity of the causes of hearing loss in Africa and other developing countries made this project successfully applicable in these countries.

In stage I, a lot of controversy is present about management of OME which is the most frequent cause of hearing loss in children (30-40\%). We put a protocol depending on meta-analysis [10] (Appendix 2) that proved the validity of antibiotics and steroids as medical treatment [13] and adenoidectomy as surgical procedure [12]. Our local studies showed that removal of peritubal adenoids relieve most of these patients [12]. Also, in recurrent cases we found that milk allergy [14] is an important factor beside recurrent peritubal adenoids. This protocol was tested in the campaign by our groups and proved its validity [10]. These findings may differ from guidelines in European countries due to different racial and ecological factors.

Another protocol was put for managing SSNHL as an emergency that threatens hearing. This protocol is based on international and local studies [5, 6] (Appendix 1). Both protocols are simple to teach, easy to apply, and saving a lot of patients from hearing loss. They also show the effect of local studies in management of

Table 2 Shows the campaigns' data outside Egypt. Six campaigns in 4 countries

\begin{tabular}{|c|c|c|c|c|c|c|c|c|c|}
\hline Date & Country/city & Hospital & Days & Trainers & Attendance & Hands on & I & ॥ & III \\
\hline 2007 & Syria: Aleppo & Al Razy Hospital & 5 & 1 & 25 & 3 & 4 & 2 & 1 \\
\hline 2009 & Palestine: Gazza - KY & European Hospital & 7 & 1 & 3 & 3 & 6 & 4 & 2 \\
\hline 2012 & Palestine: Gazza city & Al Shefa Hospital & 10 & 1 & 10 & 4 & 7 & 5 & 2 \\
\hline 2008 & Yemen/Sanaa & Kuwait Univ. H & 30 & 2 & 20 & 14 & 17 & 5 & 3 \\
\hline 2014 & Yemen/Sanaa & Kuwait Univ. H & 3 & 2 & 30 & 3 & 4 & 2 & 1 \\
\hline 11-18 Aug. 2014 & Tanzania Darussalam & Muhimbili Hosp. & 6 & 1 & 12 & 4 & 9 & 4 & - \\
\hline Sum & 6 & & 61 & $4^{*}$ & 100 & 31 & 47 & 22 & 9 \\
\hline
\end{tabular}


Table 3 Shows the campaigns' data in Yemen carried out by independent Yemeni team who were previously trained in our campaigns. The average time was 3 days for each campaign

\begin{tabular}{llllll}
\hline Serial & Town & M-year & $\begin{array}{l}\text { I } \\
\text { myring }\end{array}$ & $\begin{array}{l}\text { II } \\
\text { mastoid }\end{array}$ & $\begin{array}{l}\text { Hands on } \\
\text { trainee }\end{array}$ \\
\hline 1 & Emran & June 2007 & 15 & & 1 \\
2 & Sana'a & September 2007 & 10 & 3 \\
3 & Ebb & May 2008 & 20 & 1 \\
4 & Shabwa & July 2009 & 20 & 4 \\
5 & Attaq & 2012 & 20 & & 3 \\
6 & Sayoun 1 & December 2012 & 20 & & 1 \\
7 & Sayoun 2 & February 2013 & 9 & 4 & 1 \\
8 & Sayoun 3 & December 2014 & 9 & 4 & 2 \\
Total & 8 & & 123 & 9 & 16 \\
\hline
\end{tabular}

local health problems. Beside teaching the protocols, we provided training on peritubal adenoidectomy application of tympanostomy tubes and intratympanic injection to fulfill the aims of this stage.

We considered use of local anesthesia in ear surgery as a practical non-expensive suitable method for these campaigns. It has many advantages as better hemostasis, testing hearing, facial nerve action, and Eustachian tube patency during operation $[7,8]$ beside marked reduction of the surgical costs [9]. We had long experience to perform it at ASU.

We put soft tissue work in tympanoplasty as the main aim of training in stage $\mathrm{I}$, as it is needed in all tympanoplasty operations. This step is lacking in the TBDC training. We use tragal cartilage grafts with underlay technique. The success rate of this technique in beginners' hands is above $95 \%$, while it is less than $50 \%$ with fascia grafts [15]. Cartilage grafts need minimal blood supply and can survive with poor circulation, proving that it was stable in its bed. Although the cartilage cells may degenerate, yet the matrix remains intact. New chondrocytes may form after several years [28]. Fascia graft is considered as another option for those who prefer it. Butterfly grafts [17]are an easy procedure, but proper selection of cases is important as it has limited indication for clean small residual perforations with healthy middle ear.

Regaining ossicular continuity is mostly done with the cartilage graft itself [15] or using preserved homograft ossicles which is much cheaper easy to collect from previous operations well tolerated by human body [16].

Postoperative care, instructions for doctors and patients, and using special ointment applicator [18] can protect the graft for a long time, if there is lack of long postoperative follow-up. The practical training includes all the previously mentioned techniques, which were chosen according to our researches and experience in ASU.

The aim of the second stage was to teach different types of mastoidectomy and cholesteatoma surgery, beside the use of endoscopy in ear surgery. Attendance of previous TBDC is mandatory to share as hands on in this stage.

Mastoidectomy training includes decision-making. Non-indicated mastoidectomies are usually overdone in simple tympanoplasty after attending TBDC. Beside training how to do the operation, knowledge of different anatomical variations was explained as Korner septum, which may hide underlying pathology [29].

Cholesteatoma management protocol was previously mentioned (retrograde modified radical mastoidectomy with endoscopic control and partial cavity obliteration). We chose this technique because it was easy to apply and to teach. Besides, it is one-stage technique, low cost, and can be done under local or general anesthesia. It has a very low incidence of recidivism (residual and recurrent cholesteatoma) [20]. So, staging of the operation and long follow-up are not needed in most cases, which is suitable with the nature of surgical campaigns. In some patients, with well-pneumatized mastoid, posterior approach was used. Retrograde mastoidectomy is rarely done in TBDC programs.

The third stage included advanced training for expert surgeons and trainers, to have experience to face surgical problems in the program, also for other audience as a forward step of improving their learning curve.

The repeated well-defined steps of the same techniques or protocols make it easy to master by the trainees. Also, providing videos of the lectures and of the operations with well-explained steps showing the tips and tricks of the art helped a lot to revise the scientific material. This was obvious in some countries that were visited once, like Syria when I saw the effect and impression of the colleagues even those who did not attend the campaign. Most of the needed videos were published as free on the internet (YouTube).

Table 4 Shows the sum of the campaigns' data in Egypt, outside Egypt, and in Yemen

\begin{tabular}{|c|c|c|c|c|c|c|c|c|}
\hline Country/city & $\begin{array}{l}\text { Camp. } \\
\text { No. }\end{array}$ & Days & Attendance & Hands on & New trainers & I & $\|$ & III \\
\hline Egypt & 17 & 34 & 259 & 70 & 15 & 100 & 21 & 7 \\
\hline Other countries & 6 & 61 & 100 & 31 & 4 & 47 & 22 & 9 \\
\hline Yemen team & 8 & 24 & 30 & 16 & 16 & 123 & 9 & - \\
\hline Sum & 31 & 119 & 389 & 117 & 35 & 270 & 52 & 16 \\
\hline
\end{tabular}

About 30\% of the attendants had the opportunity to have hands on training (117/389), 30\% of them (35/117) continued to be qualified surgeons, and 17 of them were enthusiastic to be trainers 
Hotline telephone contact was established between trainees and trainers if they face any difficult situation during operation at their hospitals. This was very helpful in emergency situations, e.g., dislocated stapes, the advice was to close oval window with fascia and return stapes in place and postoperative vertigo after inner ear fistula closure, the advice was to give antibiotic and steroid injections and so on.

Analysis of results' tables showed that training an ear surgeon is tedious and long process, but it is at the end very fruitful and useful for the community. The moral contract with the trainees to spread the knowledge and to teach at least 10 younger colleagues was very useful to spread the required knowledge and experience among ear surgeons.

The fourth stage was achieved mainly by the audiology team aimed to spread prophylactic knowledge against SNHL for both doctors and patients as the effect of noise, ototoxic drugs, and vaccination against viral diseases that may cause HL. Also, the team provided suitable hearing aids (HA) to those who needed them with the help of charity associations and national insurance hospitals. Most patients needing HA are old people with presbycusis which accounts for $23 \%$ of HL in Egypt [1]. Another issue was to discover neonatal SNHL and direct them to the specialized centers for CI if indicated.

We did not concentrate on CI surgery in our campaigns, as only $1.7 \%$ of patients with HL needed it. In Egypt, it is done by several specialized centers including ASU hospitals. CI needs also long postoperative followup and training beside the high cost. The relatively high expenses can be directed to much less costly and more frequent causes of hearing loss.

The fifth stage was ambitious to put a nucleus for use of stem cells for management of severe SNHL, which may be achieved later on as a sheep alternative for $\mathrm{CI}$.

\section{Comparison with other projects}

Most previous projects which care for hearing loss problems are directed to survey the magnitude of the problem in the population [1] or in smaller sectors as neonates [30] or children [2], sometimes directed to special causes as noise induced HL. Many projects were directed to prophylactic education to avoid $\mathrm{HL}$ as viral vaccination, genetic counseling, instruction to avoid the effects of noise especially in noisy factories and music workers, also training on sign language and lip reading. Some institutes provide hearing aids. Few campaigns in Africa as in Ethiopia, Kenia, and Tanzania were directed to cochlear implants, although important but the service was expensive and given to a limited number of the deaf population (internet news).

Little efforts were directed to the major causes namely, all types of chronic otitis media COM, which represent
$55.5 \%$ of the deaf population. These are preventable and treatable causes, if we put good educational plan for both patients and doctors beside providing good training to face them, which is the main aim of this project. No previous recorded campaigns were directed to treat those patients or to train doctors to treat them. Probably, this project is the first recorded one to achieve this aim on national level.

Cooperation between different health authorities is important to achieve maximum benefit. This includes university professors providing expert trainers, local studies about the problem, and how to manage it, beside the ministry of health providing local trainees and hospital equipment and charity societies providing financial support.

\section{Advantages of this project}

This project has a lot of advantages including: (1) it manages a real national health problem in Egypt which has higher incidence than other countries and may lead to speech and teaching problems in children. Besides, it has a global comprehensive view of the HL problems, giving more attention to the more frequent causes. (2) It is based on trustful survey of the causes of HL in Egypt [1] and it treats the most frequent causes of deafness in Egypt, Africa, and most Arab countries. (3) The protocols and methods of management depend on evidence-based medicine (meta-analysis, systematic reviews) also on local researches done in ASU, which is more suitable to our patients. (4) Our protocols beside being scientific they were simple, depending on repeatable fixed standard steps as possible making them easy to apply and learn. Besides, it provides gradual increase of microsurgical abilities of the candidates and covers the training defects that are not practiced in TBDC (mainly soft tissue work). (5) The program has low cost that is suitable for developing countries. (6) Cooperation with the enthusiastic ENT departments' members of the ministry of health hospitals was the main factors of success. Also, cooperation with ASU was very helpful as it provides the expert trainers, research programs, HL survey, TBDC for the candidates, rehabilitation, and hearing aids for old patients and CI program for those who need it. (7) Follow-up of the candidates, with the results of management, allowed to improve the guidelines of the protocol. A hot telephone line was set between the candidates and their trainers to have a guide during surgical operations if difficult situations arise.

\section{Conclusion}

Training an ear surgeon is a tedious and long process, but it is at the end very fruitful and useful for the community. Most causes of HL are preventable. We think that our project plan to combat HL is very suitable to be applied in developing countries in Africa and the Middle East. 


\section{Appendix}

Appendix 1: Protocol for management of Idiopathic Sudden SNHL

Prof. Dr. Mohamed El-Begermv, Ain Shams University Cairo Egvpt, 2007.

I- Recognition and diagnosis

II-Immediate treatment:

1- Intratympanic injection of corticosteroids for 3 successive days

2- The used corticosteroids include:

Dexamethasone (available concentrations are $4 \mathrm{mg}$ till $12 \mathrm{mg} / \mathrm{ml}$, (Decadron) sometimes mixed with Methylprednisolone Acetate $40 \mathrm{mg}$ (Depo-Medrol)

3- Injection procedure: Local anesthesia with lidocaine spray $10 \%$ or gel, followed by intra-tympanic injection of $0.7 \mathrm{ml}$ dexamethasone, use insulin syringe with a long thin spinal needle.

4- Alternative procedure: Urgent Myringotomy + Grommet tube insertion (done under local anesthesia) + Intra tympanic instillation of corticosteroids three times daily by the patient for one week.

5- The ear remains up for 30 minutes after injection or drops.

6- Intravenous injection of $5 c c$. of lidocaine $2 \%$ daily for 10 days

III- long term treatment:

7- Full dose systemic corticosteroids: (begin with $60 \mathrm{mg}$ prednisolone with gradual withdrawal tapering dose for $2-3$ weeks)+ prophylactic antacidcontrol hypertension \& Diabetes)

8- Cinnarizine (Stugeron)_25 mg. tab. Twice daily for 3 month

IV-Follow up audiometry

every 3 days in the $1^{\text {st }}$ week, then every week for 1 month 


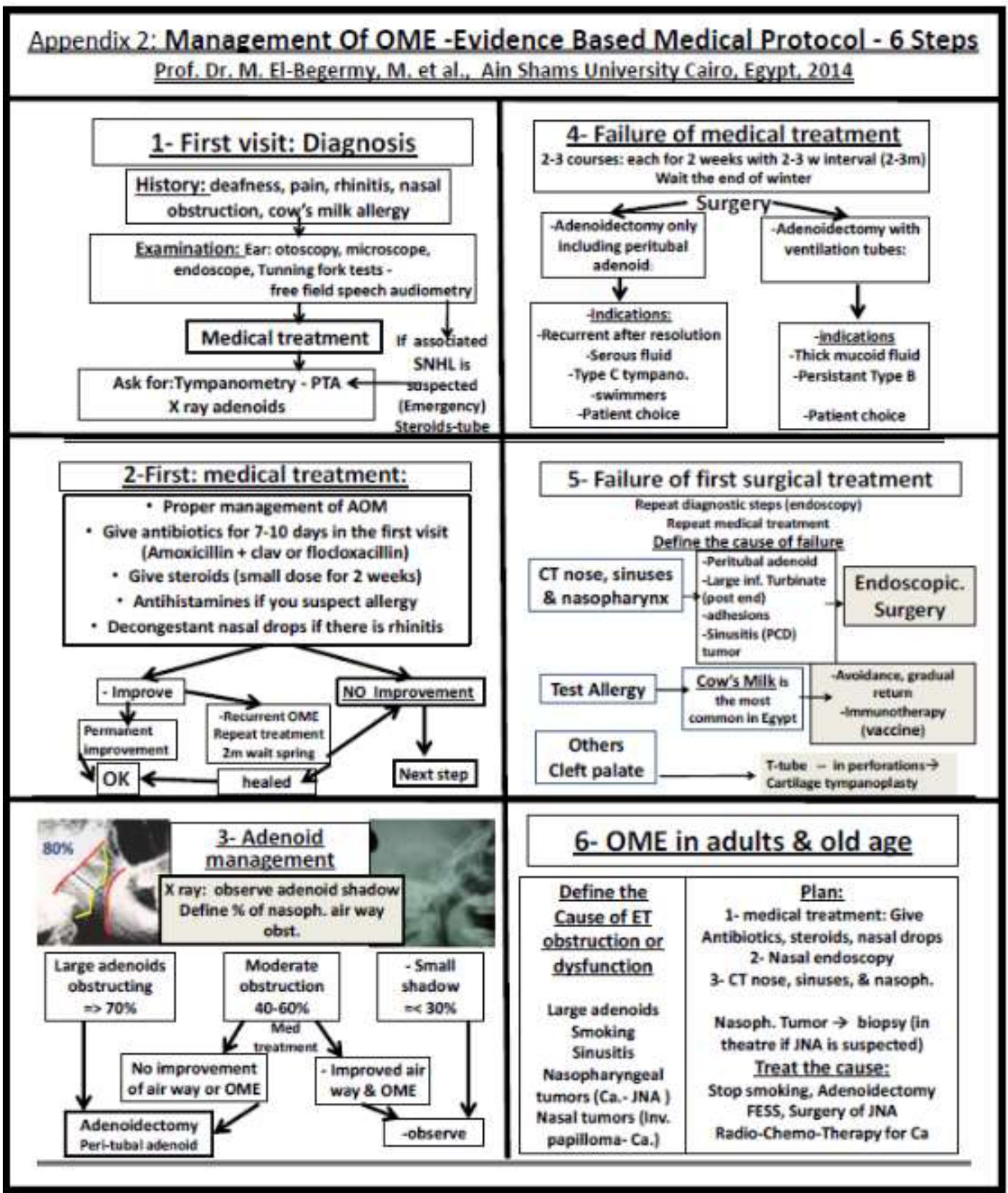

Appendix 2 Management of OME -evidence based medical protocol - 6 Steps 


\section{Abbreviations}

ABR: Auditory brain stem response; AME: Atelectatic middle ear; ASU: Ain Shams University; CHL: Conductive hearing loss; Cl: Cochlear implant; CSOM: Chronic suppurative otitis media; CWD: Canal wall down;

ED: Eustachian tube dysfunction; HL: Hearing loss; IMA: Islamic Medical Association; LA: Local anesthesia; ME: Middle ear; OAE: Otoacoustic emission; OME: Otitis media with effusion; PTA: Pure tone audiometry; SNHL: Sensory neural hearing loss; SSNHL: Sudden sensory neural hearing loss;

TBDC: Temporal bone dissection course; TM: Tympanic membrane

\section{Acknowledgements}

We acknowledge all who contributed in the project from Egypt (2010-2015): from the Ministry of Health: Gamal El-Gendy, Hany A Deghady from Shebeen Elkom Teaching Hospital, Nasr El-Seidy from Samanoud, Ibrahim Abdel Hadi, Nasr El-Seidy, Nasr Mohamed Nasr from Banha Teaching Hospital, Ahmed Osman, Mohamed Atteia, Moussa Zayed from Damanhour, Samir Haleem, Karam A Aleem from Almataria Teaching Hospital, A Monem El-Mougy from Alsahel Teaching Hospital, and Yasser Nafie, audiology consultant. Other expert contributors, Egypt: Abdelrahman Ezzat from Al Azhar University Cairo, Al Azhar U. Damietta ENT department members, Marwa M. El-Begermy, Hany Kassamy from Ain Shams University, Magdy Omar, Hany Deghady fom Shebeen Elkom Elhilal Hospital, IMA Hospitals Staff Shebin AlKanater, Suhag Insurance Hospital staff, Allaa el Behairy, Momen Ibraheem from Kafr el-Sheikh, Mohamed Fawzy, Ashraf Amer from Al Mahalla, Omar Ghanem, AbdelShafi Sawy from Assuit.

Contributors abroad: Al-Assad Spec. Hospital staff from Taiz, Yemen (19972008). AbdulWasa AlAgel, Moh. Saleh Mosleh, Ahmed Futaini, Samir AlSharaabi, and Fouad Shamsan from Univ of Science and Technology Hosp, Sanaa, Yemen. AbdulWahab Nasr, Ashwaq Alabsi, and Mohamed Azazi from Kuwait Hospital, Sanaa Univ., Yemen. Al Razy Hospital ENT dep, Saad Alnayef, Hazem Kaheel, Aleppo, Syria (2007), Ihab Zayyan, Nahid AIMasri, Salih Saker from European Hospital team, Gazza, Palestine (2009,) Hussein Ashoor, Eisa Mossalam from Al Shefa hospital team, Gazza, Palestine (2012), Muhimbili National Hosp, Dar ELSalam, Tanzania (2014).

To all those who shared in this project as attendants, trainers, inviters, administrators and to those who are going on the road, whether I mentioned or forget to mention, thank you.

The manuscript or its content has not been published or is being considered for publication elsewhere except previous presentation at the Egyptian ORL Society, Otology on Nile Conference, Cairo, Egypt, December 2012, and Federation of Islamic Medical Associations (FEMA) Conference. Arusha, Tanzania, August 2014

\section{Authors' contributions}

$M B$ is the main author and program leader. He is the owner of the idea of the project, put the plan for its implementation, supervised training on temporal dissection courses and live surgeries, and was the main trainer of the trainers, shared in collecting data, data analysis, and writing of the manuscript. HD shared in planning, shared in surgical training, and data collection. NE shared in planning, shared in surgical training, and data collection. AE shared in planning, shared in surgical training, and data collection. MMB shared in planning, shared in surgical training, and data collection and analysis and writing of the manuscript (corresponding author). AA shared in surgical training and data collection. MSM shared in surgical training and data collection. YN shared in audiological evaluation and data collection. All authors read and approved the final manuscript.

\section{Funding}

No funding was obtained for this study.

\section{Availability of data and materials}

All data generated or analyzed during this study are included in this published article.

\section{Ethics approval and consent to participate}

All procedures performed were in accordance with the ethical standards of the Ain Shams University research ethics board and/or national research committee and with the 1964 Helsinki declaration and its later amendments or comparable ethical standards. Informed consent was obtained from all individuals for surgical procedures and participation in the project.

\section{Consent for publication}

Not applicable.

\section{Competing interests}

The authors declare that there are no competing interests.

\section{Author details}

${ }^{1}$ ENT department, Ain Shams University, Cairo, Egypt. ${ }^{2}$ Ministry of Health, Shebin El kom Teaching Hospital, Shebin El kom, Egypt. ${ }^{3}$ Ministry of Health Banha Teaching Hospital, Banha, Egypt. ${ }^{4}$ ENT department Al Azhar University, Cairo, Egypt. ${ }^{5}$ Science and Tech. Univ., Sanaa, Yemen. ${ }^{6}$ Audiololgy consultant, Alemadi Hospital, Doha, Qatar.

Received: 3 April 2020 Accepted: 13 July 2020

Published online: 14 October 2020

\section{References}

1. Hamid O, Khatib OM, Aly A, Morad M, Kamel S (2007) Prevalence and patterns of hearing impairment in Egypt: a national household survey. East Mediterr Health J 13(5):1170-1180

2. Hamid O, Shokry T, Shehata W (2010) Prevalence and pattern of hearing loss in house-held national survey in Egypt. EJENTAS 11:12-16

3. Mulwaful W, Kuper H, Ensink R (2016) Systematic review: prevalence and causes of hearing impairment in Africa. Trop Med Int Health 21(2):158-165

4. WHO deafness and hearing loss: WHO, News room. 2020. https://www.who. $\mathrm{int/news-room/fact-sheets/detail/deafness-and-hearing-loss.}$

5. El-Begermy M, Massoud M, El-Samny T (2001) Use of IV lidocaine in treatment of idiopathic sudden SNHL. Egypt J ENT Allied Sci 2(1):23-27

6. Hamid M, Hamid O, Tawfiq S, Mohamed SK, Kamal I (2015) Intra-tympanic corticosteroid for the treatment of primary immune-mediated sensorineural hearing loss. EJENTAS 16:243-245

7. El-Begermy M, Abd E-KA (1990) High adrenaline concentration with local anesthesia in ear surgery. In: Proceedings of symposium on recent trends in anesthesia and intensive care; industrial Jubail City. Al-Fanateer Hospital, KSA, pp 1-13

8. El-Begermy M, El-Begermy MM, Rabie AN, Ezzat A, Sheesh A (2016) Use of local anesthesia in ear surgery: technique, modifications, advantages and limitations. Thirty years' experience. Egypt J Otolaryngol 32(3):161-169

9. Ghanem AM. Cartilage tympanoplasty (type1) by local anaesthesia "costs and results". Thesis submitted for partial fulfillment of MS degree in ORL. Supervised by: El-Begermy M, Salam F, El Gohary M. Cairo, Egypt: Al Azhar University; 2003

10. El-Begermy M. Management of otitis media with effusion OME - evidence based protocol. Proceedings of The Third Annual Scientific Meeting of Damietta Society of Otorhinolaryngology. Port Saied, Egypt; 2014.

11. El-Begermy M, Massoud M, El-Fiky L, Sorour N (2001) The value of otoendoscopy in diagnosis and treatment of otitis media with effusion (OME). Egypt J ENT Allied Sci 2(1):1-6

12. El-Begermy M, Amer A, Sheesh M (2000) Role of peritubal adenoid enlargement in the etiology of otitis media with effusion (OME) and role of nasal endoscopy in its management. EJENTAS. 1(1):15-22

13. Wahba H, Fattoh S, Asal A (2009) Meta-analysis of the role of corticosteroids in the management of otitis media with effusion. J Int Adv Otol 5(2):151-157

14. Abul-Ezz TA. Otitis media with effusion and food allergy. Thesis submitted for partial fulfillment of MD degree in ORL. Supervisors: Elsamaa M, ElBegermy M, Medany M, Refaat M, Shafik A. ENT Dep. Ain Shams University. Cairo, Egypt. 2005.

15. El-Begermy M, Sorour N, Ezzat WF, Rasslan M (2001) Use of homologous and autologous cartilage grafts in the treatment of tubo- tympanic type of simple chronic suppurative otitis media. EJENTAS. 2(2):73-83

16. El-Kahky MS, Mousa S, El-Sayed S, El-Begermy M, Refaee A, Yousef A, Sabry M, Rabie N (1987) A comparative study between the fate of preserved and freshly implanted ossicular homografts and heterografts in Guinea pigs. Egypt Med J 70(1-4):175-185

17. Kaya I, Murat Benzer M, Uslu M, Bilgen C, Kirazli T (2018) Butterfly cartilage tympanoplasty long-term results: excellent treatment method in small and medium sized perforations. Clin Exp Otorhinolaryngol 11(1):23-29

18. El-Begermy M (1992) A new alternative in treatment of otitis externa (ointment applicator). J Laryngol Otol 106:855

19. El-Begermy M, Ibrahim S, El-Halabi H (2001) Cartilage tympanoplasty in attico-antral type of chronic otitis media. EJENTAS. 2(2):63-72 
20. El-Begermy M, Amer A, El-Aquel A, El-Beltagy Y (2005) Role of endoscopic control with canal wall down (CWD) in decreasing cholesteatoma recidivism. EJENTAS 6(1):45-54

21. El-Begermy M, Rabie N, Abdel-Latif OH, Ibrahim S, Mansour O (2007) Minimizing cavity problems in canal wall down cholesteatoma surgery by using one stage partial obliteration. EJENTAS. 9(2):57-69

22. El-Begermy M. Endoscopic assisted stapedectomy. The $17^{\text {th }}$ World Congress of the International Federation of Otolaryngologic Societies (IFOS). Sep.-Oct. 2002; p. 400

23. Abdel Mageed HM. Update of pathogenesis and management of tympanosclerosis, essay submitted for partial fulfillment of Master Degree in ORL. Supervisors: Rabie N, El-Begermy M., Fawaz S. ENT department, Ain Shams University, Cairo, Egypt. 2006.

24. El-Begermy M, Elhakeem H, Ibrahim S et al (2019) Management of atelectatic middle ear using cartilage graft and Eustachian tube recanalization under publication

25. El-Begermy MA, Mansour OI, El-Makhzangy AM, El-Gindy TS (2009) Congenital auditory meatal atresia: a numerical review. Eur Arch Otorhinolaryngol 266:501-506

26. El-Begermy M, Mansour O, Adly A, Samer Ibrahim S, El-Beltagy M (2008) Role of otoendoscopy in management of glomus tympanicum. EJENTAS 10(1):11-18

27. El-Begermy M: Save Hearing Project. Egyptian ORL Society, Otology on Nile Conference, Cairo, Egypt, December 2012, and Federation of Islamic Medical Associations (FEMA) Conference. Arusha, Tanzania August 2014.

28. Hamed M, Samir M, El-Bgeremy M (1999) Fate of cartilage material used in middle ear surgery. Light and electron microscopy study. Auris nasis larynx 26:257-262

29. El-Begermy M, El-Beltagy Y, Amer A, Mabrouk A, Sinna M (2005) Korner's septum: clinical, radiological and cadaveric study. EJENTAS 6(1):1-10

30. Elbeltagy R, Bakry H, Waly E (2019) Hearing loss-related knowledge and attitude toward neonatal hearing screening among Egyptian parents. Egypt J Otolaryngol 35:207-212

\section{Publisher's Note}

Springer Nature remains neutral with regard to jurisdictional claims in published maps and institutional affiliations.

\section{Submit your manuscript to a SpringerOpen ${ }^{\circ}$ journal and benefit from:}

- Convenient online submission

- Rigorous peer review

- Open access: articles freely available online

- High visibility within the field

- Retaining the copyright to your article

Submit your next manuscript at $\boldsymbol{\nabla}$ springeropen.com 